\title{
Vulnerabilidad derivada de los procesos de urbanización periférica y su relación con el medio natural. Estudio de caso: corredor vial del AMGR
}

\author{
Prof. Mg. Alberto, Jorge Alfredo \\ Centro de Geociencias Aplicadas (CGA) e Instituto de Geografia (IGUNNE) - UNNE \\ E-mail: jaalberto@hotmail.com \\ aalberto@hum.unne.edu.ar
}

\section{Resumen}

Para el desarrollo del presente trabajo se ha seleccionado un área del ámbito periurbano del Gran Resistencia localizada a unos $20 \mathrm{~km}$. al norte del mismo. Dicha área en los últimos años ha presentado fuertes cambios en relación al uso del suelo, donde el elevado parcelamiento y la existencia de diferentes infraestructuras estarían indicando una fuerte presión de la ocupación con todas la problemáticas ambientales derivadas de ello.

Teniendo en cuenta esta problemática se trabaja una metodología para el estudio del paisaje integrado, apoyada en una concepción del paisaje geográfica y sistémica. El modelo utilizado responde a la necesidad de analizar y caracterizar el proceso de urbanización incipiente; valiéndose para ello de bases cartográficas de síntesis e históricas, fotografías aéreas, imágenes satelitales orientadas al uso de herramientas informáticas

\section{Palabras claves:}

Vulnerabilidad, crecimiento urbano, espacios periurbanos, espacios naturales relictuales.

\section{Vulnerability due peripheral urbanization processes and its relationship with the natural environment. Case study: the AMGR road corridor}

\section{Summary}

In order to develop the present study, we selected a periurban area located $20 \mathrm{~km}$ towards north of the Gran Resistencia city. This area supported important changes in land use during the last years. The extreme proccesses of land dividing into plots as well as the infrastructural different frameworks indicates a strong pressure derived from human occupation. This procces originated several problems related with this situation. Over this natural and human problematic scenary, we overcome the study using a methodology that applied the integrated landscape geographical study. The methodology is supported as well in the sistemic and geographical landscape conception.

The model used embraces too the necessity of analyze the incipient urban proccesses. In this order, we employed basical synthesis chartographic maps as well historic ones. Also, we employed aerial photographies and satellitary images addressed to the use of informatic tools concerning with these problems

\section{Key words}

Environment management, periurban environment. 


\section{INTRODUCCIÓN}

La diversidad de uso del suelo de las área periféricas del Gran Resistencia que sumado al aumento de las incidencias del mismo sobre el espacio en muy corto tiempo, se han transformado en uno de los problemas ambientales de mayor preocupación de los últimos años para los especialistas en planificación. (BARRETO, M., 2002). Para el estudio de esta problemática se aplica una metodología para el estudio del paisaje integrado, apoyada en una concepción del paisaje geográfica y sistémica (IBARRA BENLLOCH, P., 1993). El método utilizado responde a la necesidad de analizar y caracterizar el proceso de urbanización incipiente; valiéndose para ello de bases cartográficas de síntesis e históricas, fotografías aéreas, imágenes satelitales orientadas al uso de herramientas informáticas que permitan analizar y evaluar las diferentes variables ambientales. En el mismo, se analizaron los aspectos positivos y negativos desde el punto de vista ambiental del proceso espontáneo de ocupación del sistema natural y antrópico del área en cuestión; situación que posibilitó determinar las principales problemáticas ambientales que permitieron conocer las principales variables que controlan el proceso de ocupación, y en consecuencia, plantear posibles pautas de gestión que propendan a lograr las condiciones deseables de ocupación del espacio.

\section{UBICACIÓN DEL ÁREA DE ESTUDIO}

Para el desarrollo del presente trabajo se ha seleccionado un área del ámbito periurbano del Gran Resistencia que se organiza a partir de la ruta Nacional $n^{\circ}$ 11, la cual se comporta como un corredor transversal, que condiciona la ocupación y organización del espacio a través de diferentes formas de usos del suelo de la superficie sujeta a estudio. Fig.1. 


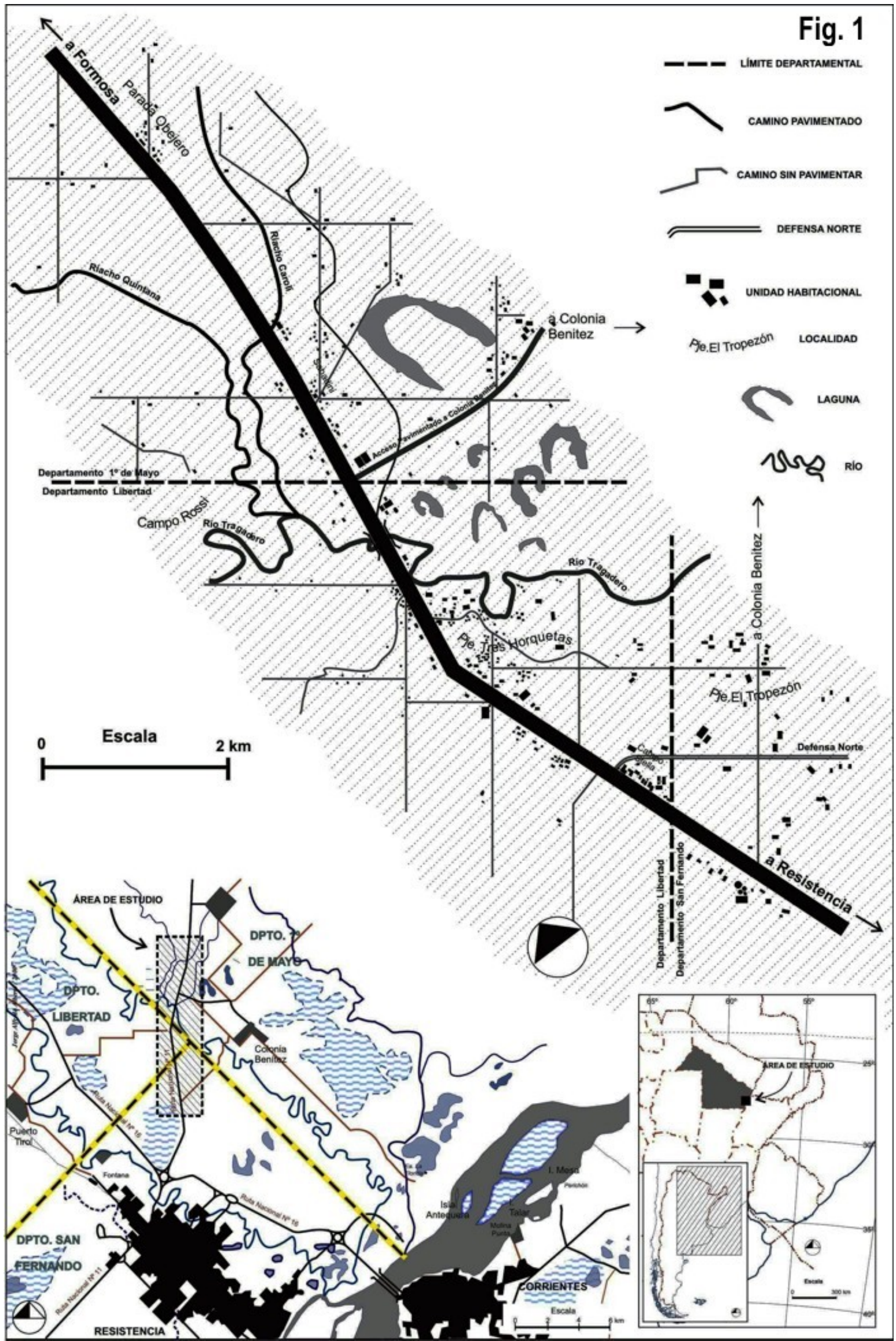


En la misma se encuentran poblados como Tres Horquetas y Paraje El Tropezón, a lo que se suman incipientes núcleos de urbanización como el acceso pavimentado a Colonia Benitez, Campo Stella, Parada Obejero, Estación Sabadini entre otros.

\section{CARACTERIZACIÓN}

\subsection{DINÁMICA DEL SISTEMA NATURAL.}

En detalle, el área de estudio es una planicie de acumulación que sustenta paleomodelos fluviales periódicamente inundables (fig. 2). Comprende específicamente parte de la cuenca del río Tragadero asentada sobre paleoderrames, cuyos rasgos dominantes son los continuos y progresivos procesos generalizados de erosión y sedimentación que están complementados con la colmatación de biomasa muerta (POPOLIZIO, E., 1989). Estas condiciones dan lugar a una heterogeneidad interna que permiten determinar una diferenciación de zonas subordinadas entre sí; según se detalla: 


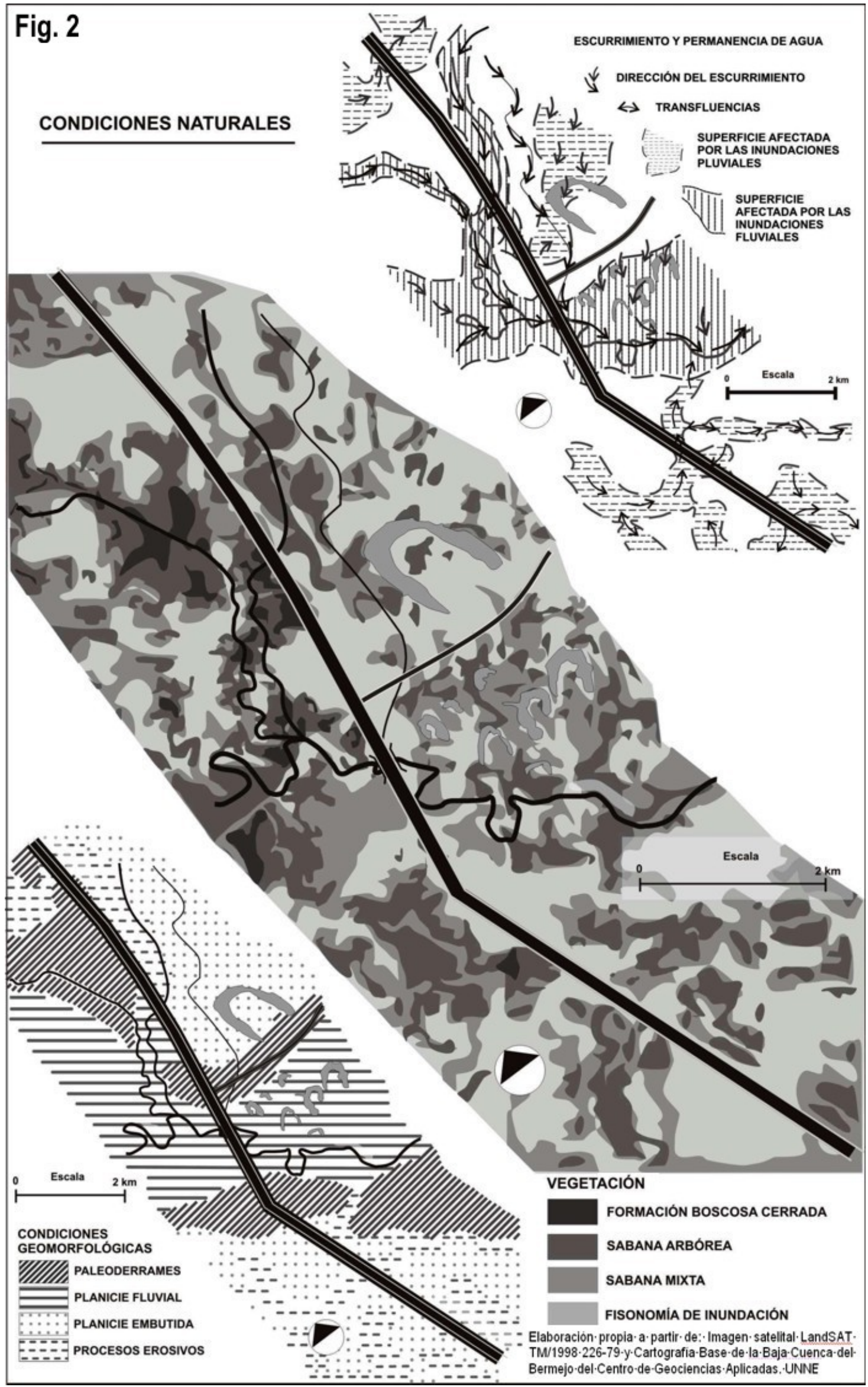


a. Zona de Paleoderrames: Son el resultado de la existencia de enormes paleoconoides aluviales del Bermejo que se superpusieron al modelado estructural originando numerosos brazos divergentes, con derrames laterales que sobreelevaron de la planicie, sustentando, en la actualidad, formaciones boscosas y dejado entre ellos planicies embutidas.

b. Zona de Planicie Fluvial (o de Divagación): Es el valle o área de ambientes anegadizos retrabajados por el río Tragadero y sus afluentes dentro de los paleoderrames. En los mismos se observan la presencia de áreas boscosas atomizadas, con predominio de leñosas en las áreas más elevadas, que degradan periféricamente en abras, pudiendo estar asociadas a formaciones mixtas. Sobre los albardones elaborados por el río Tragadero o los riachos Quintana y Carolí crecen formaciones boscosas denominada bosque en galería o de ribera que guarda cierta analogía con los denominados monte alto. Posee características heterogéneas conformadas por árboles de gran porte (20 a 30 metros de altura) debajo de los cuales crecen arbustos, lianas, helechos, cardos, orquídeas, etc., presentando suelos arenosos, aireados y bien drenados.

c. Zona de Planicies Encerradas (o Embutidas): La misma se caracteriza por tener terrenos encerrados por de los diferentes regueros o paleoderrames. Dichos terrenos se comportan como cubetas donde el escurrimiento hídrico es lento y de permanencia temporal debido a la escasa pendiente. Estas condiciones determinan la presencia de ambientes permanentes o periódicamente anegadizos donde predominan gramíneas duras, de los géneros Elionorus, Andropogón, Panicum, Paspalum y otras plantas herbáceas, especialmente Compuestas y Leguminosas. Entre estos se intercalan ambientes de menor extensión no inundables, ocupados por coberturas leñosas que se encuentran agrupadas en formaciones boscosas cerradas con abras de pajonales $u$ otras higrófilas, que pueden estar asociadas a paleoformas fluviales y eólicas. 


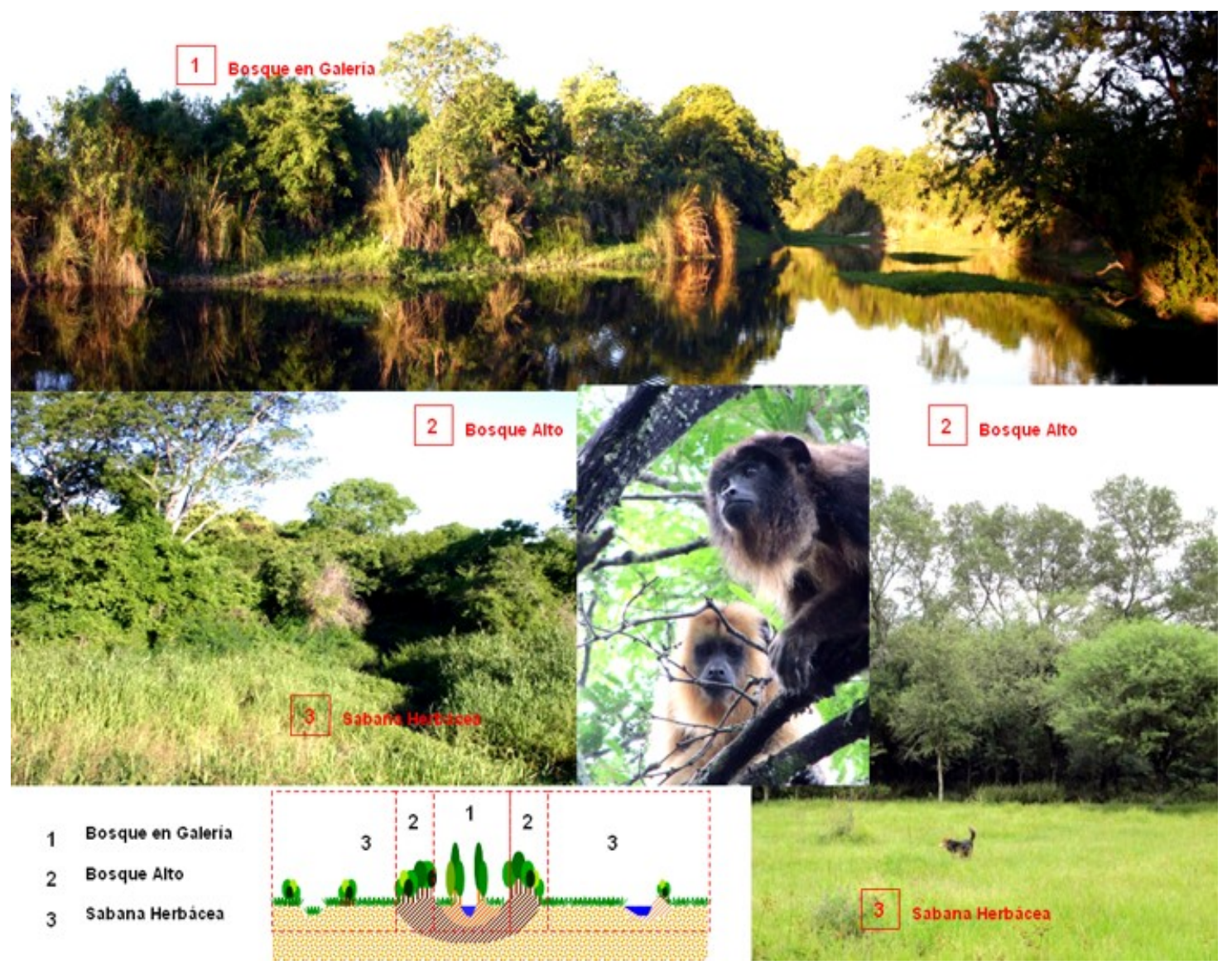

\subsection{DINÁMICA DEL USO DEL SUELO}

El área de estudio es parte de antiguas colonias agrícolas - forestales como Colonia Benitez y Margarita Belén, distantes a 17 y 21 km. de Resistencia respectivamente y aproximadamente $7 \mathrm{~km}$. entre sí. A mediados de la década del 80 se realiza el acceso pavimentado a Colonia Benítez junto con la construcción de barrios de viviendas dentro de los pueblos, situación que con el correr del tiempo se acentúo con nuevos planes del Fonavi, Banco Hipotecario y sistemas de autoayuda, sustentados por subsidios brindados por el gobierno de la provincia del Chaco. Gran parte de estos barrios fueron construidos sobre terrenos bajos, ubicados al noreste del pueblo. En este periodo se da una marcada reconversión en lo que se refiere a la producción agrícola, donde el cultivo del algodón y del tabaco son reemplazados por la horticultura a cargo de empresas familiares que contribuyen al abastecimiento de productos fresco al Gran Resistencia. A fines de la década del 90 la 
construcción de la Defensa Norte en la zona en el Paraje El Tropezón, dentro del área de estudio, dio lugar por un lado a un fuerte parcelamiento de tierras para su venta, y por otro, a una revalorización de las mismas sujetas a la cotización de la oferta y la demanda. La incipiente construcción de viviendas no sólo como residencias permanentes, sino también con fines de recreación y esparcimiento, ha sido acompañada por una fuerte transformación del paisaje debido a la generación de praderas artificiales y bosques monoespecíficos de especies exóticas; lo que evidencia una revalorización de las tierras no por su valor o aptitud productiva, sino por su valor fiscal o urbano. Cabe agregar que hasta 1985 la ocupación y parcelamiento de tierra con fines urbanos se realizó sobre la ruta Nacional $n^{0} 11$ y la antigua entrada a Colonia Benitez. A partir de 1985 hasta 1998 aproximadamente, la tasación inmobiliaria se mantiene por su proximidad al Gran Resistencia, pero los mayores loteos y procesos de compra y venta se traslada hacia la nueva entrada a Colonia Benitez, también conocida como Acceso Pavimentado, ubicada a más de $7 \mathrm{~km}$. de la antigua entrada. Nuevamente la zona vuelve a tener auge a partir 1998, cuando se inician las obras del Plan de Defensa con la apertura de caminos, donde se profundizan los fraccionamientos de tierras, muchos de ellos evadiendo el fisco. Esta situación de acelerado parcelamiento de grandes predios en lotes (no superiores a los 30 por 50 metros) se acentúa en los últimos años con la construcción del "Acueducto Margarita Belén - Colonia Benítez" y el proyecto de trazado de la "Autovía" sobre la ruta 11, hechos que incrementa la especulación inmobiliaria con exagerados valores del metro cuadrado por el interés que surge sobre esta zona, que podría decirse se ha puesto de moda como "esparcimiento de fin de semana" dando lugar a casas-quinchos, country y barrios cerrados.

\section{IDENTIFICACIÓN DE PROBLEMÁTICAS}

Como se ha mencionado en apartados anteriores, para la identificación de las problemáticas se parte de un enfoque integrado y sistémico del paisaje (fig. 3), con lo pretensión de brindar lineamientos para el ordenamiento ambiental que el sistema territorial debe alcanzar. 


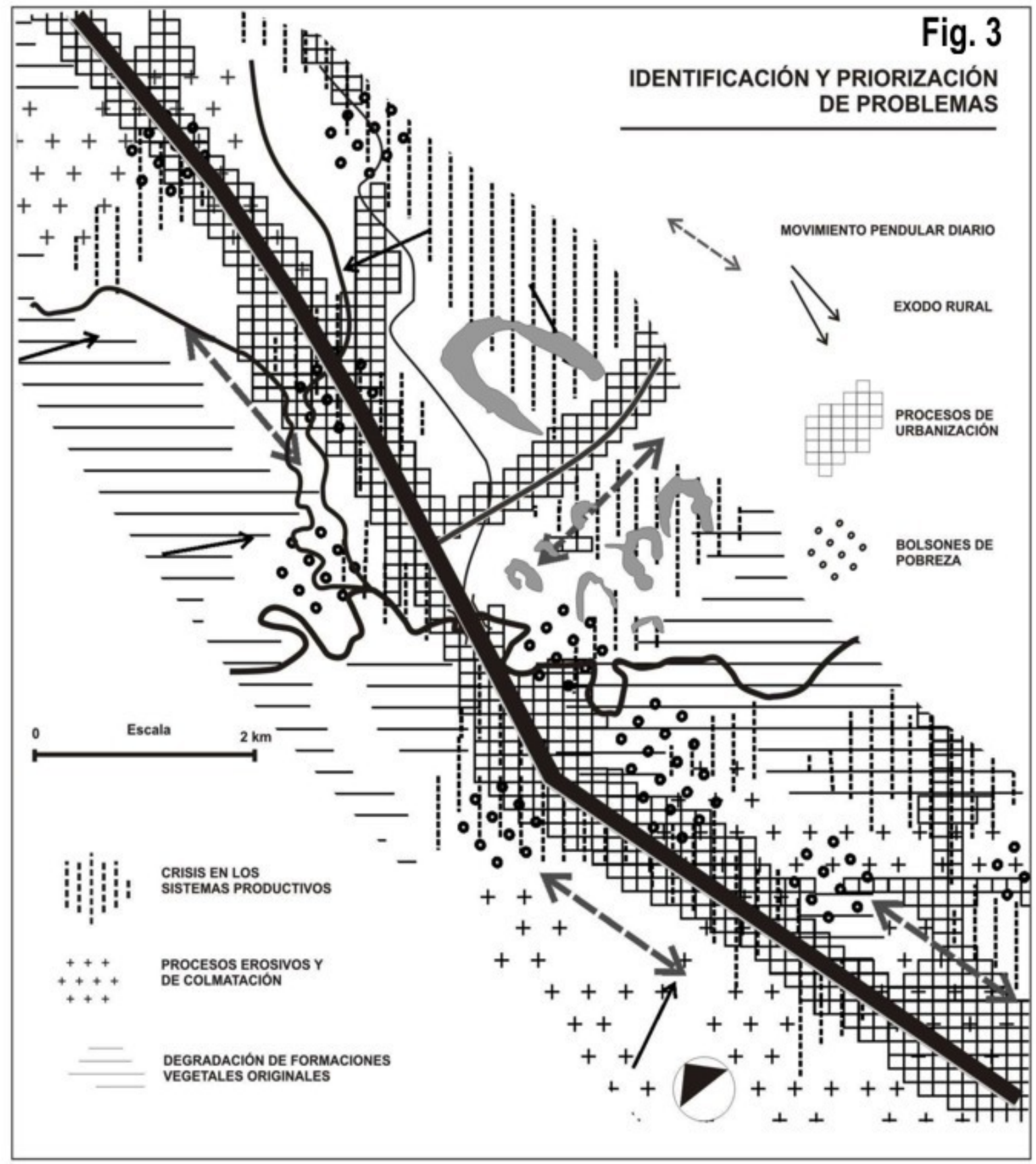

Para dicho planteo se trabajó sobre dos grandes sistemas, el natural y el antrópico (fig. 4); en el primero se tuvo en cuenta solamente aspectos físicos y biológicos que caracterizan el comportamiento del área de estudio, sin por ello pasar por alto la acción humana sobre los mismos. En cambio, el sistema antrópico se organizó a partir de cuatros aspectos dinámicos e interrelacionados entre sí: el productivo (explotación forestal, ganadera, agrícola, hortícola e industrial), el inmobiliario, la población y las infraestructuras y servicios (ROMA PUJADAS y JAUME FONT, 1998). 


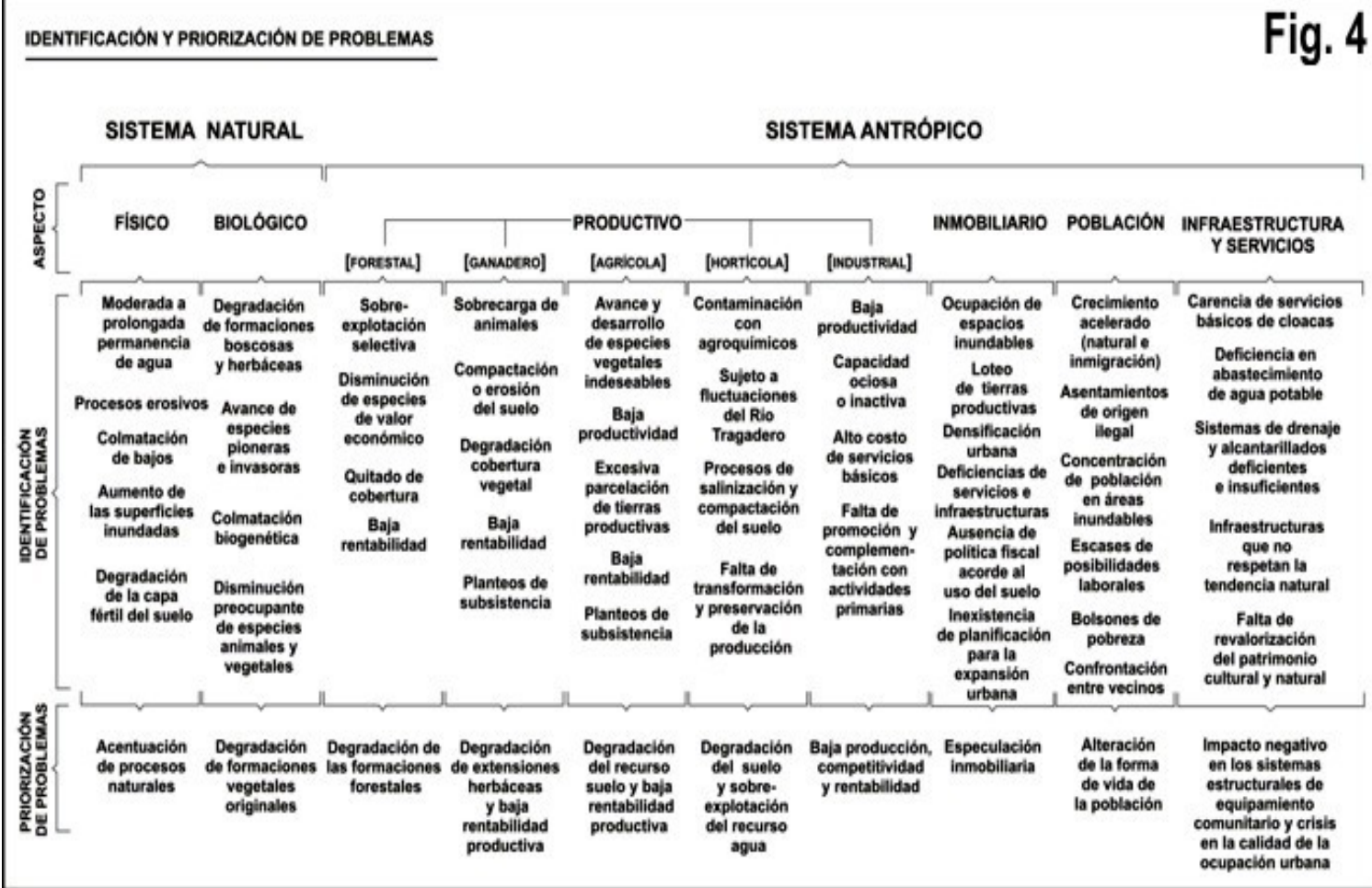

En relación al sistema natural, tanto el aspecto físico como el biológico presentan una fuerte degradación del medio ambiente, resultado de la acentuación de procesos naturales (erosión, colmatación, inundación) y la alteración de las formaciones vegetales originales a través de la acción antrópica (dilapidación, sobreexplotación, avance de invasoras, extinción).

Con respecto al sistema antrópico, en el aspecto productivo, que implica las actividades primarias y de transformación, la mayor parte de los problemas identificados están relacionados con la degradación del medio por sobreexplotación, erosión, compactación, contaminación y enfermedades, sumados a la escasa rentabilidad económica productiva del mismo por falta de coordinación y complementación de la explotación a nivel predio, a lo que se añade la escasa transformación, preservación, promoción y comercialización de los productos obtenidos.

En el aspecto inmobiliario se hace referencia a los fines de ocupación del suelo. En el mismo, se observa una alteración de las cualidades espaciales por una ocupación anárquica, resultado de una acentuada especulación inmobiliaria, que responde, en primer lugar, a un acelerado crecimiento 
demográfico y a una densificación urbana por procesos migratorios de ámbitos rurales cercanos y de la ciudad de Resistencia, y en segundo lugar, por su proximidad en distancia y tiempo a esta última, la cual, en las décadas del 80 y 90 ha tenido un rápido crecimiento de la población y del espacio urbanizado.

En el aspecto demográfico se visualiza un crecimiento acelerado de la población, la que se concentra en núcleos ubicados en los parajes Tres Horqueta y El Tropezón. Gran parte de esta proviene de ámbitos rurales aledaños, donde las actividades agrícolas se encuentran en una situación de crisis y recesión; aunque en los últimos años, como se comentó más arriba, se observa una marcada tendencia de población proveniente del Gran Resistencia en busca de esparcimiento o con fines residenciales, proceso acompañado por un movimiento pendular por cuestiones laborales.

En el aspecto de infraestructuras y servicios, las problemáticas observadas son el resultado del marcado crecimiento de la población y el acelerado aumento de las superficies urbanizadas, complementadas con procesos de ocupación de espacios rurales con fines productivos. Se observa que en ámbitos rurales éstas no respetan la tendencia natural en la mayoría de los casos y en ámbitos urbanos se nota la carencia de servicios básicos de cloacas, situación que demuestra una notoria pérdida en la calidad de vida de los pobladores. 


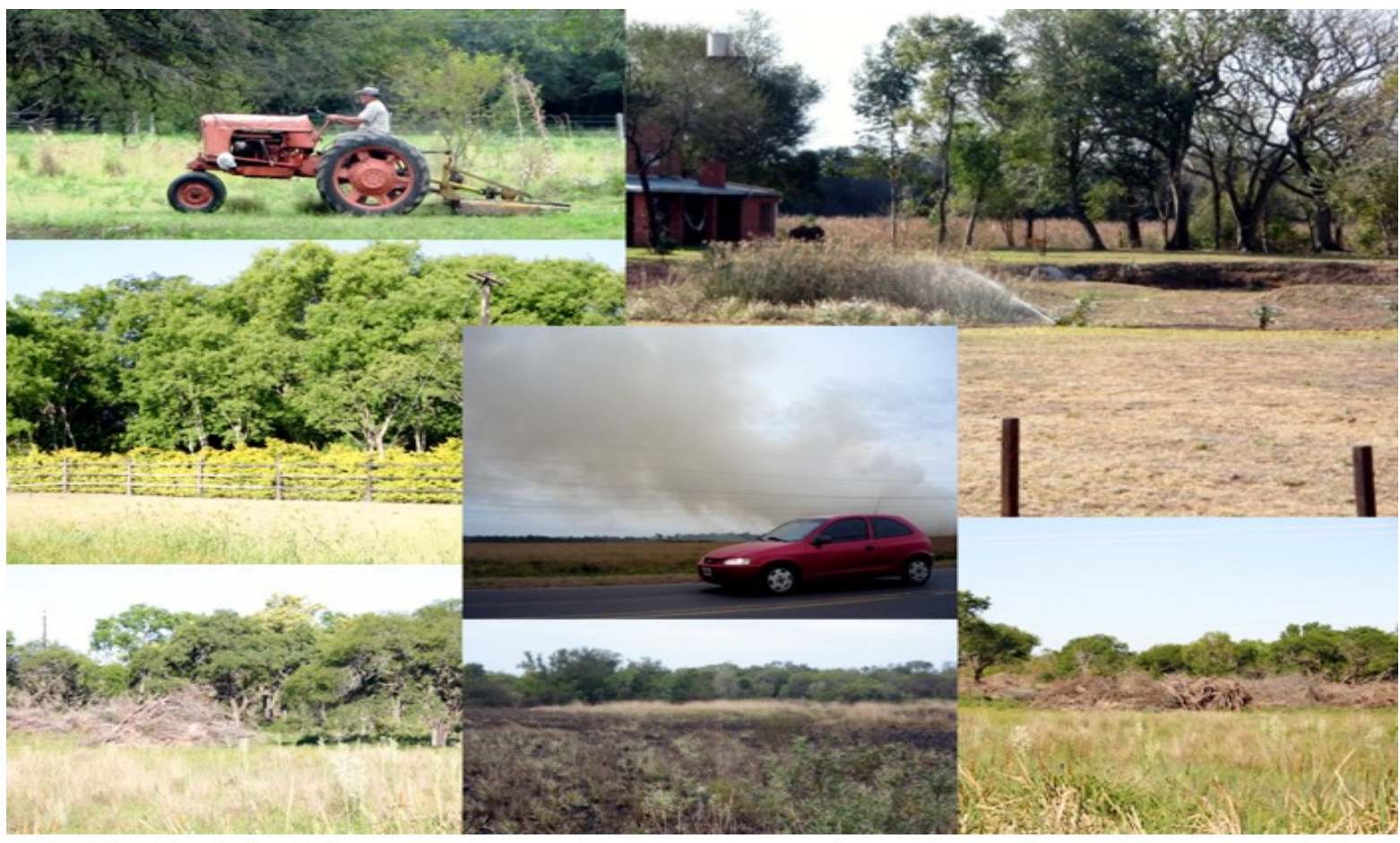

Artificialización del paisaje con praderas y bosques monoespecíficos de especies endógenas y exógenas
indistintamente a partir de topado, desmalezado, incendios o implantación de especies con riego aspersión con una fuerte presión a la napa freática
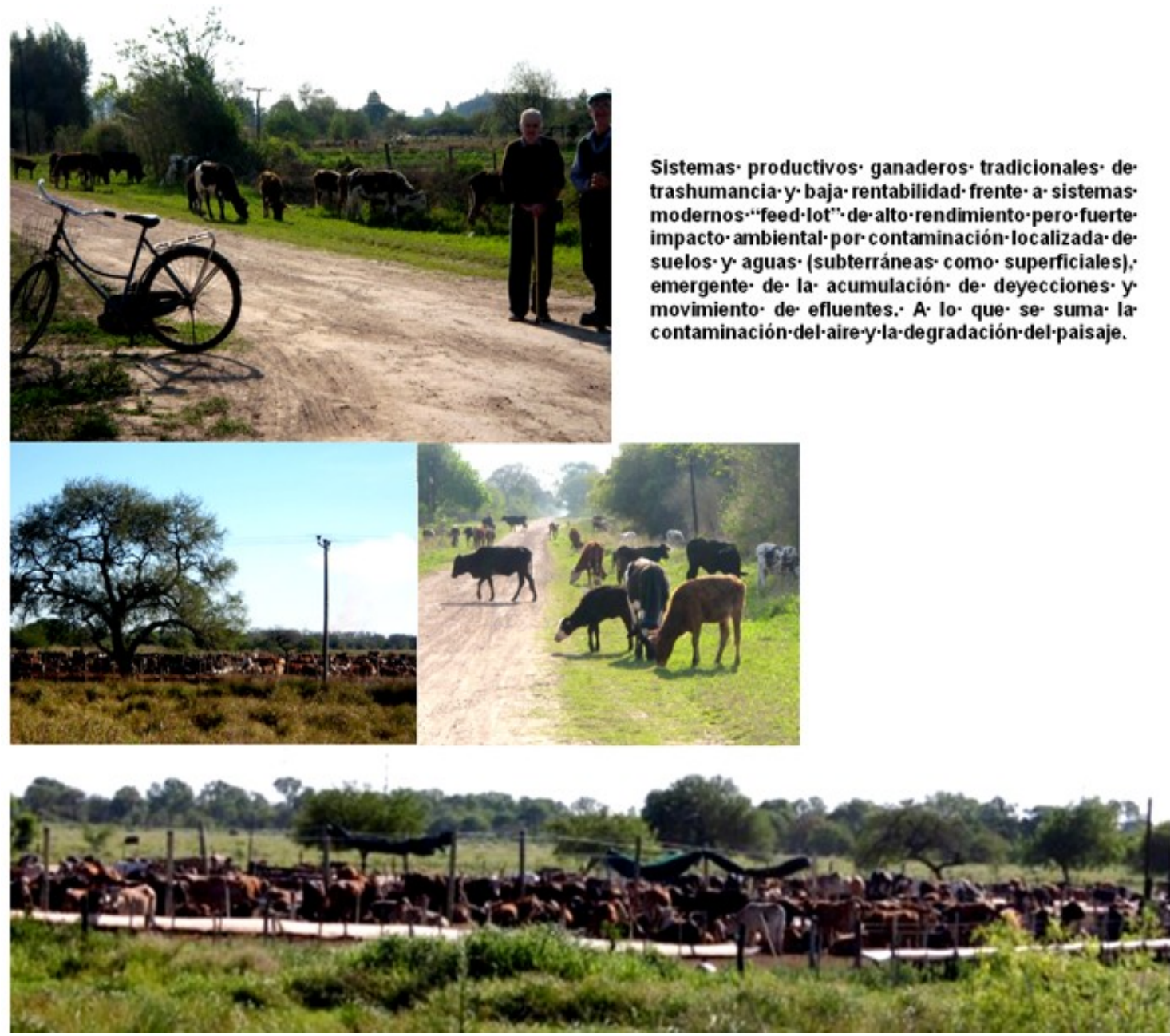


\section{ANÁLISIS DE PROBLEMAS}

Para analizar los problemas detectados se procedió a la realización de cuatro árboles que reflejan las problemáticas más importantes de la zona (fig. 5). Cada uno compuesto de un problema central (el tronco), con sus causas (problemas iniciales o raíces) y efectos (problemas derivados o ramas). Los mismos se detallan a continuación:

El problema central del Árbol de problema $n^{\circ} 1$ es la degradación total del medio natural original en su conjunto que responde a la sobreexplotación y mal manejo que se han hecho del mismo, situación que dio lugar en la actualidad a la baja rentabilidad de la explotaciones.

El Árbol de problema $\mathbf{n}^{\circ} \mathbf{2}$ hace referencia a los sistemas productivos ineficientes en cuanto a rentabilidad y sostenibilidad. El mismo responde a problemáticas ya detalladas en el árbol de problemas $n^{\circ} 1$, vinculadas al mal manejo o sobreexplotación de los recursos naturales, por planteos poco propicios de los sistemas productivos y de comercialización.

El tercer problema analizado en el Árbol de problema $\mathbf{n}^{\circ} \mathbf{3}$, es la alteración de las cualidades espaciales, debido a la acentuación de los procesos migratorios provenientes de ámbitos rurales próximos y del Gran Resistencia consecuencia de las problemáticas ya detalladas en el árbol $n^{\circ} 1$ y 2. Esto genera un proceso de densificación urbana que deriva en una marcada pérdida en la calidad de vida de sus habitantes.

El cuarto problema aparece en Árbol de problema $n^{\circ} 4$, consiste en la pérdida de la calidad de vida de los pobladores de la zona, provocada por las alteraciones de las cualidades espaciales (tanto desde el punto de vista natural como socioeconómico); lo que deriva en la acentuación de este problema central. 

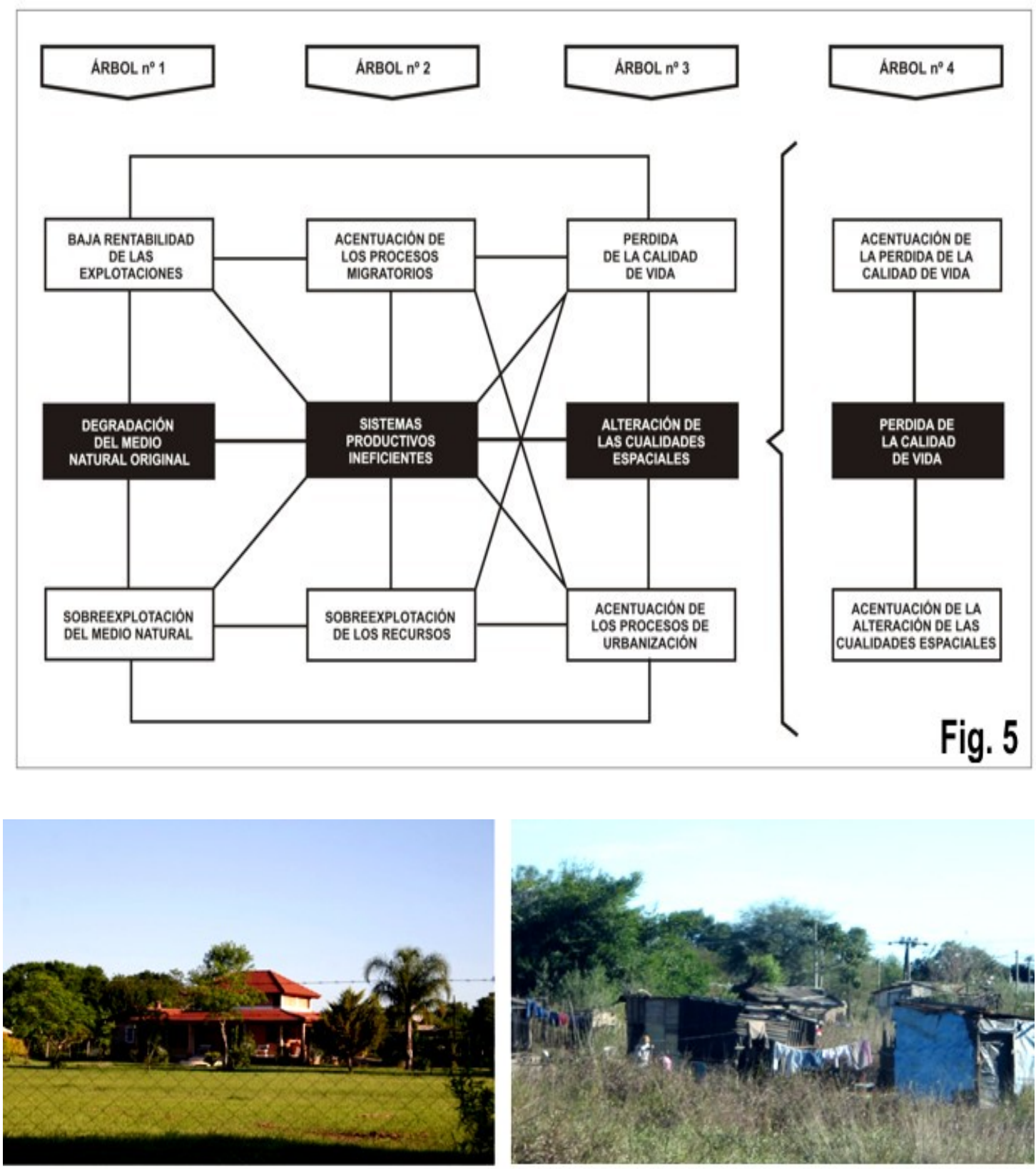

Ocupación anárquica resultado de un acelerado crecimiento demográfico y a una densificación urbana por procesos migratorios de ámbitos rurales cercanos y de la ciudad de Resistencia
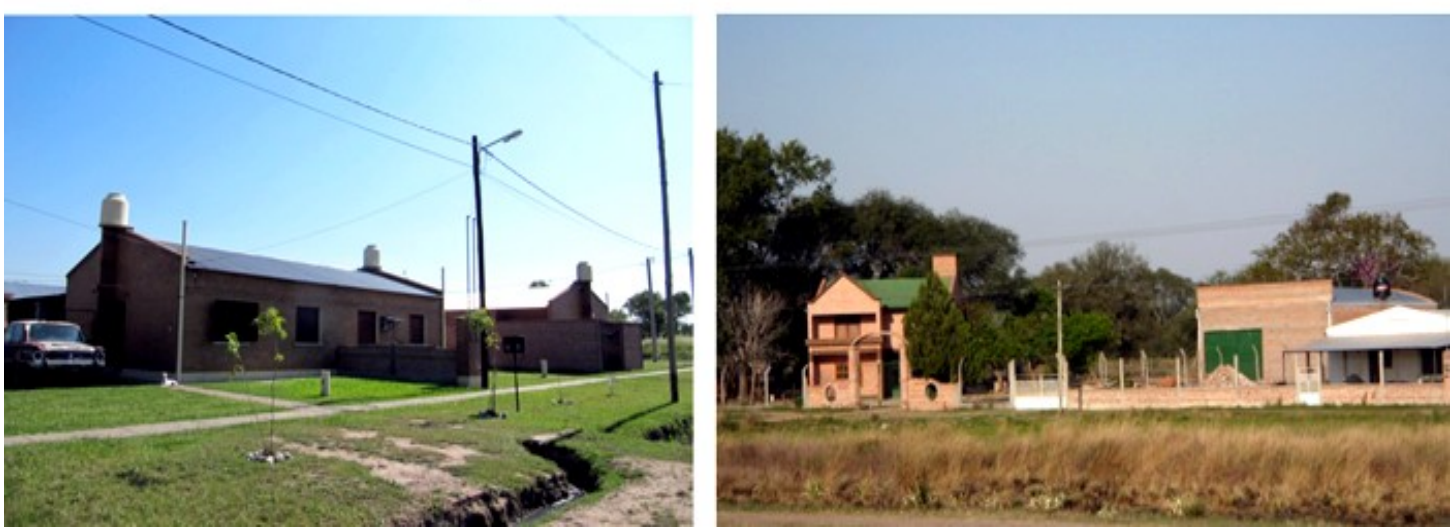


\section{CONCLUSIONES}

El área sujeta a estudio presenta una estructura de espacio agropecuario disgregado a partir de los marcados procesos de urbanización, vinculados a una red urbana organizada por el Gran Resistencia. En la misma, a partir del análisis de los problemas detectados y analizados se manifiesta la necesidad de:

- La planificación de la tierra con fines residenciales o de inversión, que limite la especulación inmobiliaria y permita un crecimiento urbano acorde al contexto rural.

- La disminución de la alteración de las cualidades espaciales, a partir de establecer límites a la ocupación anárquica del espacio, cuyo efecto, permitiría mejorar y mantener la calidad de vida de los pobladores.

Teniendo en cuenta los aspectos antedichos, en relación a las estructuras vinculantes entre el sistema productivo rural y el proceso de urbanización incipiente que inciden sobre el área de estudio, surge la necesidad de profundizar e insistir en las líneas de acción futuras como:

- Desarrollar sistemas productivos novedosos, alternativos, complementarios y diversificados que exploten los recursos locales de manera sustentable.

- Definir y potenciar centros críticos de desarrollo económico local (Roccatagliata, j., 1998), poniendo el esfuerzo en identificar núcleos urbanos que presenten un potencial desarrollo en apoyo de las actividades agropecuarias.

- Proponer medidas enérgicas para limitar la expansión urbana en las zonas agrícolas fértiles, conservándolas para la producción de alimentos y como espacios libres de contaminación.

\section{BIBLIOGRAFÍA}


1. AlBERTO, Jorge A. (2003). Ordenamiento Ambiental de un espacio rural sujeto a la presión del Crecimiento Urbano: Estudio de un caso del AMGR. Tesis Maestría en Gestión Ambiental. FAU-UNNE.-

2. ALBERTO, Jorge A. (2005). Problemáticas ambientales resultantes de la ocupación urbana en ambientes fluviolacustres. Estudio de caso: Área Metropolitana del Gran Resistencia (AMGR). En Revista Geográfica $n^{\circ}$ 138. julio - diciembre 2005. . Instituto Panamericano de Geografía e Historia (IPGH). Mexico DF. pp. 109 - 127

3. Alberto, Jorge A. (2008). La fragmentación territorial y la degradación ambiental como efectos de la expansión del Área Metropolitana del Gran Resistencia (AMGR). [Monografía en CD-ROM] X Jornadas Cuyanas de Geografía La Geografía Frente a la Necesidad de Integrar Territorios y Voluntades. Instituto y Departamento de Geografía de la Facultad de Filosofía y Letras de la Universidad Nacional de Cuyo. Mayo 28 - 31. Mendoza, Argentina.

4. Alberto, Jorge A. (2010). Análisis socioespacial de la vulnerabilidad ambiental resultante del crecimiento urbano sobre ambientes fluviolacustres. [Monografía en CD-ROM] Seminario Internacional de Población y Sociedad en América Latina. SEPOSAL. 10 de Junio 2010. Salta. Argentina.

5. ALBERTO, Jorge A. y SCHNEIDER, V. (2006). Análisis de la dinámica del crecimiento urbano del Gran Resistencia. Estudio de caso. Reunión de Comunicaciones Científicas y Tecnológicas. SGCyT / UNNE. Resistencia. Octubre 2006.

6. Alberto, Juan A. (2007) Vulnerabilidad Ecológica y natural. En: Foschiatti, Ana Maria (Eds.) "Aportes conceptuales y empiricos de la vulnerabilidd global". Resistencia. EUDENE. UNNE. Resistencia. Argentina.pp. 117 - 158.

7. BARRETO, M. (2002). El crecimiento de las ciudades Intermedias del NE Argentino en el contexto de las transformaciones regionales. En: Cuaderno Urbano No 3, FAU-UNNE.

8. DOLLFUS, Oliver (1978) El análisis geográfico. Colección ¿qué sé? Nueva Serie. Oikos - tau. (Barcelona) España. 
9. GAMIR ORUETA, A, RUIZ PÉREZ, M., SEguí PONS, J. M. (1995) Prácticas de análisis espacial. Oikos - tau. (Barcelona) España.

10. GOMEZ OREA, D. (1985). El espacio rural en la ordenación del territorio. Instituto de Estudios Agriarios, Pesqueros y Alimentarios. Madrid.

11. GOMEZ OREA, D. (1992). Planificación rural. Ed. Agrícola Española. Madrid.

12. IBARRA BENLLOCH, P. (1993). Una propuesta metodológica para el estudio del paisaje integrado. En Geographicalia 30. Revista del Departamento de Geografía y Ordenación del Territorio. Universidad de Zaragoza. 229-242. Diciembre 1993.

13. Ministerio de Obras Públicas, Transporte y Medio Ambiente. (1995) Guía metodológicas para la elaboración de estudios de impacto ambiental., Series monográficas. Ministerio de Obras Públicas, Transporte y Medio Ambiente. Secretaría de Estado de Medio Ambiente y Vivienda. Madrid, (España).

14.POPOLIZIO, E. (1989). Algunos elementos geomorfológicos condicionantes de la organización espacial y las actividades del NEA, Geociencias no XVII, Centro de Geociencias Aplicadas, U.N.N.E., Resistencia.

15. ROCCATAGLIATA, J. (1998). Ordenamiento Territorial y Sistemas de Ciudades. Documento del curso: "La Gestión Ambiental en el Desarrollo Urbano". Maestría de Gestión Ambiental del Desarrollo Urbano GADU. Facultad de Ingeniería. Universidad Nacional del Comahue. Neuquén.

16. ROMA PUJADAS y JAUME FONT (1998). Ordenación y Planificación Territorial Espacios y Sociedades. Serie Mayor. Editorial Síntesis. (Madrid) España. 